\title{
Design and performance of a cm-scale shrouded wind turbine for energy harvesting
}

\author{
D.A. Howey ${ }^{1}$, A. Bansal ${ }^{2}$, A.S. Holmes ${ }^{2 *}$ \\ 1. Mechanical Engineering Department, Imperial College London, \\ Exhibition Road, London SW7 2AZ, UK \\ 2. Department of Electrical and Electronic Engineering, Imperial College London, \\ Exhibition Road, London SW7 2AZ, UK
}

\begin{abstract}
A miniature shrouded wind turbine aimed at energy harvesting for power delivery to wireless sensors in pipes and ducts is presented. The device has a rotor diameter of $2 \mathrm{~cm}$, with an outer diameter of $3.2 \mathrm{~cm}$, and generates electrical power by means of an axial flux permanent magnet machine built into the shroud. Fabrication was accomplished using a combination of traditional machining, rapid prototyping, and flexible printed circuit board technology for the generator stator, with jewel bearings providing low friction and start up speed. Prototype devices can operate at air speeds down to $3 \mathrm{~m} / \mathrm{s}$, and deliver between $80 \mu \mathrm{W}$ and 2.5 $\mathrm{mW}$ of electrical power at air speeds in the range $3 \mathrm{~m} / \mathrm{s}$ to $7 \mathrm{~m} / \mathrm{s}$. Experimental turbine performance curves, obtained by wind tunnel testing and corrected for bearing losses using data obtained in separate vacuum rundown tests, are compared with the predictions of an elementary blade element momentum (BEM) model. The two show reasonable agreement at low tip speed ratios. However, in experiments where a maximum could be observed, the maximum power coefficient ( $\sim 9 \%)$ is marginally lower than predicted by the BEM model and occurs at a lower than predicted tip speed ratio of around 0.6.
\end{abstract}

Keywords: energy harvesting, air turbine, wind turbine, microturbine, wireless sensor, axial flux generator Classification numbers: 47.85.-g, 88.50.G-, 07.07.Df

\footnotetext{
*Corresponding author, email a.holmes@imperial.ac.uk, tel. +44 (0)20 75946239
} 


\section{Introduction}

Flow-driven energy harvesters could provide a useful source of power to replace or supplement batteries in a range of wireless sensor applications, for example in air conditioning systems or remote gas pipelines. The electrical power delivered by a flow-driven harvester placed in a free stream may be expressed as:

$$
P_{\text {out }}=\eta C_{p} \cdot 1 / 2 \rho A U_{0}^{3}
$$

where $A$ is the device cross-section, $U_{0}$ is the free stream flow speed, $\rho$ is the fluid density, $C_{p}$ is the fraction of the fluid power extracted as mechanical power within the harvester, and $\eta$ is the efficiency with which this raw mechanical power is converted to electrical output power. The power coefficient $C_{p}$ has a maximum theoretical value of 16/27 $=0.593$, the so-called Betz limit [1], and large scale wind turbines can approach this level of performance while at the same time achieving very high mechanical-to-electrical conversion efficiency. Miniaturised energy harvesters are expected to have lower $C_{p}$ values, primarily because of high viscous losses at low Reynolds numbers, and downscaling can also lead to an increase in other losses. Nevertheless, it should be feasible to generate useful power levels from $\mathrm{cm}$-scale devices. For example, assuming an overall efficiency of $\eta C_{p}=0.1$, which is a reasonable target value, a harvester placed in an air stream will generate $160 \mu \mathrm{W} / \mathrm{cm}^{2}$ at a flow speed of $3 \mathrm{~m} / \mathrm{s}$, increasing to $3.1 \mathrm{~mW} / \mathrm{cm}^{2}$ at $8 \mathrm{~m} / \mathrm{s}$. This range of flow speeds is typical for an air handling duct [2].

Miniaturisation of the classical wind turbine is a natural starting point for the development of small air flow harvesters, and in recent years a number of groups have demonstrated devices based on this approach. For example, in a 2003 publication, Federspiel and Chen [3] combined a $10.2 \mathrm{~cm}$-diameter fan rotor, a brushless DC motor operated as a generator, and a 3-phase bridge circuit to produce a device that could deliver $8 \mathrm{~mW}$ at $2.5 \mathrm{~m} / \mathrm{s}$ air speed and $28 \mathrm{~mW}$ at $5.1 \mathrm{~m} / \mathrm{s}$. More recently, Rancourt et al. [4] have demonstrated a smaller device, with a $4.2 \mathrm{~cm}$-diameter rotor, that delivers powers of $2.4 \mathrm{~mW}$ and $130 \mathrm{~mW}$ at air speeds of $5.5 \mathrm{~m} / \mathrm{s}$ and $11.8 \mathrm{~m} / \mathrm{s}$ respectively. Existing commercial rotor and generator parts were used in both of these devices. Myers et al [5] have developed a custom piezoelectric generator which, when coupled to three $12.7 \mathrm{~cm}$ diameter fan rotors via a crank assembly, can deliver $5 \mathrm{~mW}$ of output power at a flow rate of $4.4 \mathrm{~m} / \mathrm{s}$. Further devices using commercial off-the-shelf components have been demonstrated in the past year by Xu et al [6] and Carli et al [7]. The first of these, which uses a $7.6 \mathrm{~cm}$-diameter plastic rotor and a brushless DC motor, can generate $13.5 \mathrm{~mW}$ at $4 \mathrm{~m} / \mathrm{s}$ air speed; the second, described only as a horizontal-axis wind turbine with a diameter of $6.3 \mathrm{~cm}$, produces $10 \mathrm{~mW}$ at $4.7 \mathrm{~m} / \mathrm{s}$ air speed.

Aside from small turbines, work has also been done on alternative types of flow-driven harvester based on flapping or vibration. Such devices are attractive in principle because they do not involve rotating parts and hence do not require reliable, low-friction bearings. For example, in 2008 Humdinger Wind Energy LLC launched a cm-scale harvester based on the "windbelt" principle, where the air flow generates aerodynamic flutter in a thin belt linked to a transducer. The " $\mu$ icroWindbelt" has a cross-sectional area of $37 \mathrm{~cm}^{2}$ and can 
deliver $0.2 \mathrm{~mW}$ and $5.0 \mathrm{~mW}$ at flow speeds of $3.5 \mathrm{~m} / \mathrm{s}$ and $7.5 \mathrm{~m} / \mathrm{s}$ respectively [8]. More recently, Zhu et al have demonstrated a resonant device consisting of an aerofoil mounted on a cantilever behind a bluff body and linked to an electromagnetic transducer [9]. This device has a cross-section of $52 \mathrm{~cm}^{2}$ and delivers 0.47 $\mathrm{mW}$ and $2.0 \mathrm{~mW}$ at air speeds of $2.5 \mathrm{~m} / \mathrm{s}$ and $6 \mathrm{~m} / \mathrm{s}$ respectively. Other devices have been demonstrated based on vortex shedding, where the vortices created behind a bluff body drive the vibration of a simple cantilever [10], and on flow-induced resonance in air-filled cavities [11]. However, up to now the overall efficiencies achieved in such devices have been extremely low.

While the results obtained to date are encouraging, they are mostly for relatively large devices which may be unsuitable for many wireless sensor applications. Furthermore, there is a very wide spread in performance. For example, considering only the turbine-based harvesters, the best performing devices $[3,4]$ achieve overall efficiencies up to around $10 \%$ (i.e. $\eta C_{p} \approx 0.1$ ), while the worst performing [5] has an overall efficiency of about $0.25 \%$. Most of the devices are relatively inefficient and consequently larger than they should be given their power output. This is a reflection of the fact that no serious effort has been devoted to optimising the turbine and generator designs at small scale. For non-turbine designs, the spread of performance is even wider, with overall efficiencies ranging from about $1 \%$ [9] down to $0.0016 \%$ [10].

Recently at Imperial College we have been developing a miniature turbine-based harvester aimed specifically at duct monitoring applications. The device comprises a $2 \mathrm{~cm}$-diameter shrouded turbine with an axial-flux permanent magnet (AFPM) generator integrated into the shroud. The overall cross-sectional area including the shroud is only $8 \mathrm{~cm}^{2}$, which represents only $1.1 \%$ of the cross-section of a $1 \mathrm{ft}$ diameter duct. Figure 1 shows exploded and sectional views illustrating the device geometry and construction. Details of the fabrication process and preliminary performance data were reported previously in [12], and a complete battery-less wireless sensor using the turbine as a power source has been reported in [13]. In the present paper, details of the turbine design are presented, and additional wind tunnel test results are reported for an improved device with reduced losses. Bearing loss measurements have also been made, allowing an improved estimate of the turbine performance, and comparison with the predictions of an elementary blade element momentum (BEM) model of turbine performance. 


\section{Scaling considerations}

This section briefly reviews the scaling laws for turbines and electromagnetic generators as these have important implications for generator sizing at $\mathrm{cm}$-scale and smaller. The key variables in wind turbine design are the turbine shaft power $P_{\text {shaft }}$, the rotational speed $N$, the free stream flow speed $U_{0}$, the rotor diameter $D$, the roughness of the machine surfaces $\varepsilon$, and the fluid properties (density $\rho$, viscosity $v$ ) [1]. Since there are 7 variables and 3 fundamental dimensions, 4 non-dimensional groups can be formed as follows:

$$
P_{\text {shafi }} /\left(\pi \rho D^{2} U_{0}^{3} / 8\right)=f\left\{N D / 2 U_{0}, N D^{2} / 4 v, \varepsilon / D\right\}
$$

The group $P_{\text {shaff }} /\left(\pi \rho D^{2} U_{0}{ }^{3} / 8\right)$ is the power coefficient $C_{p}$ in equation (1) if, as is normally the case, $A$ is taken to be the area swept out by the rotor; $J=N D / 2 U_{0}$ is the tip speed ratio, i.e. the ratio of blade tip speed to free stream flow speed; $R e_{\Omega}=N D^{2} / 4 v$ is the rotational Reynolds number, and $\varepsilon / D$ the relative roughness. Therefore this set of functional relationships can be expressed as:

$$
C_{p}=f\left\{J, \operatorname{Re}_{\Omega}, \varepsilon / D\right\}
$$

If a particular turbine design can be scaled in size so as to keep $J, \operatorname{Re}_{\Omega}$ and $\varepsilon / D$ constant, then $C_{p}$ will be invariant and the shaft power will scale according to:

$$
P_{\text {shaft }} \propto D^{2} U_{0}^{3}
$$

In practice, however, downscaling of a turbine normally leads to a reduction in $J$ and $R e_{\Omega}$, as well as an increase in $\varepsilon / D$. For a given free stream speed, in order to maintain constant tip speed ratio as the turbine size is reduced, the rotation speed has to increase as $N \propto 1 / D$, and this is generally unsustainable beyond a certain point because of speed limitations imposed by the bearings. A more likely scenario at smaller scales is therefore that $N$ is fixed at some maximum speed, and hence that $J \propto D$. In either of these cases $(J=$ const and $J \propto D$ ), assuming the fluid remains the same, the Reynolds number will decrease as the turbine size is reduced, either as $\operatorname{Re}_{\Omega} \propto D$ or as $\operatorname{Re}_{\Omega} \propto D^{2}$.

The reductions in $J$ and $R e_{\Omega}$ as a turbine is downscaled have a detrimental effect on the power coefficient, resulting in relatively poor performance in small machines. Nevertheless, empirically it is found that $C_{p}$ scales more slowly than the machine size $D$, at least down to $\mathrm{cm}$ scale; this is borne out by the examples in the introduction, some of which achieve $C_{p} \sim 0.1$ with diameter order $0.1 \mathrm{~m}$, where a large scale machine might have a $C_{p}$ of 0.5 , with diameter order $100 \mathrm{~m}$. Consequently it is expected that the scaling of the shaft power for a given free stream speed will satisfy:

$$
P_{\text {shaft }} \propto D^{(2+\delta)} \quad ; 0 \leq \delta<1
$$

For comparison, the scaling law for the output power from a small permanent magnet generator [14] is:

$$
P_{\text {out }} \propto N^{2} D^{5}
$$


In the two scenarios considered above, where the rotation speed $N$ either scales as $1 / \mathrm{D}$ or is fixed, the generator output power will scale either as $P_{\text {out }} \propto D^{3}$ or $P_{\text {out }} \propto D^{5}$. In both cases, comparing these results with (5), the generator output power will down-scale more quickly with reduction in machine size than the turbine shaft power. This suggests that below some particular size the generator will need to be larger than the turbine in order for the two to remain matched in terms of power rating, contrary to the normal situation in large-scale machines. This effect has been demonstrated previously in a $1 \mathrm{~cm}$-diameter MEMS turbine, where it was found that an AFPM integrated near the axis of this device was unable to apply any significant loading to the turbine [15]. For this reason, the present device was designed as a shrouded turbine with the generator integrated into the shroud and hence outside the turbine.

\subsection{Reynolds number effects and aerofoil performance}

The wind turbine presented here was designed primarily for deployment in air conditioning ducts where a free stream speed in the range $2<U_{0}<10 \mathrm{~m} / \mathrm{s}$ can be expected. The device was sized to ensure no more than $\sim 1 \%$ obstruction of a $1 \mathrm{ft}$-diameter duct, leading to a turbine diameter of $D=2 \mathrm{~cm}$ (allowing for the generator), and the blade chord was set at $c=3 \mathrm{~mm}$ to allow experimentation with variable blade number up to 12. It was assumed during the design phase that rotational speeds up to ca $15,000 \mathrm{rpm}$ might be achievable, although in experiments the rotation speed was limited to 5,000 rpm.

Over the range of practical rotational speeds (i.e. up to 5,000 rpm), and with $2<U_{0}<10 \mathrm{~m} / \mathrm{s}$, the maximum tip speed ratio that can be reached by a wind turbine with $D=2 \mathrm{~cm}$ is $J=2.6$, while with $c=3 \mathrm{~mm}$ the Reynolds number based on the blade chord length $\left(R e_{c}=N D c / 2 v\right)$ never exceeds about 2,000. For comparison, a 'domestic' scale wind turbine such as that used on a house or yacht typically operates at $\operatorname{Re}_{c} \approx$ 60,000 , while a megawatt scale wind turbine might operate at $R e_{c} \approx 3 \times 10^{6}$ or higher. Although these machines also operate at higher $J$, it is the effect of down-scaling on $R e_{c}$ that is most significant. Aerodynamics at low Reynolds numbers are considerably different to aerodynamics at higher values. The flow is laminar or transitional rather than turbulent, and aerofoils operating in this regime exhibit performance worse than that of aerofoils in the fully turbulent regime $[16,17]$ due to increased viscous drag losses and boundary layer separation. In comparison to laminar boundary layers, turbulent boundary layers are able to withstand greater adverse pressure gradients without separation because the effective viscosity of a turbulent boundary layer is higher than that of a laminar layer. At low Reynolds numbers, separation occurs much more easily and may even take place at the leading edge of the aerofoil.

Aerofoil performance is generally specified in terms of the lift and drag coefficients, $C_{L}$ and $C_{D}$, which give the lift and drag forces per unit area, normalised to the dynamic pressure of the incident airstream. Kunz et al. [18], using two-dimensional CFD simulations, have predicted that for $\operatorname{Re}_{c}<10,000$ significant lift $C_{L}$ is still attainable using thin aerofoils with camber, but the lift-to-drag ratio is severely reduced [16]. In particular, it was found that $C_{L}$ values up to 0.5 can be achieved at $R e_{c}<6,000$ but that drag is increased by an order of magnitude compared to high Reynolds number aerofoils, resulting in lift to drag ratios below 10 . 
Lift and drag data generated by Kunz et al for a NACA4402 aerofoil profile at $R e_{c}=2,000$ was used in the design of the turbine that is the focus of this paper.

Although 2D aerofoil performance is a good starting point for many turbine designs, the rotor is spinning and this imposes additional forces on the fluid. Work on large wind turbines suggests that the effect of rotation on aerodynamic performance is generally beneficial, e.g. stall is postponed [19], but the actual 3D flow regime depends strongly on the blade chord to pitch ratio and twist angle [20]. At very low Reynolds numbers, Kunz [21] suggests that there are significant differences in actual spanwise power and blade loading compared to that predicted with 2D methods. Nonetheless, 2D methods remain useful for initial order of magnitude design estimates.

\section{Design and fabrication}

\subsection{Turbine design}

Given the non-linearity of the Navier Stokes equations and the complexity of the air-flow around a turbine it is not possible to analyse the behaviour analytically and therefore numerical or empirical methods of performance prediction must be used. The most general numerical method is Computational Fluid Dynamics (CFD) which has been used extensively in both wind turbine and gas turbine design. However, full analysis of a moving rotor problem with shroud is complex and requires transient simulation on a large computational grid to resolve the geometry correctly, as well as a moving mesh to capture the interaction between moving and stationary components. This was outside the scope of the current project. Instead, a simpler approximate method, known as the Blade Element Momentum (BEM) method, was used. The method is described in many textbooks (see for example [22]), but the essential details are included below.

In the BEM method a rotor blade is treated as a series of radial elements which are spinning aerofoil sections each of which contributes torque; the total shaft torque is found by integrating the contributions from hub to tip. The problem is assumed to be axi-symmetric and radial forces and airflow are ignored. Referring to Figure 2, as the air with free-stream speed $U_{0}$ passes through the rotor disc, it is axially decelerated, and also has tangential swirl imparted to it in reaction to the torque imparted to the rotor. These axial and tangential fluid accelerations are represented by axial and tangential induction factors, $a$ and $a$, which are assumed to be functions of radius $r$. These factors are found by iterative solution at each radial position, for a specific blade pitch angle $\beta$ (which may also vary with radius) and rotor speed $\omega$. The torque contribution from a radial section $\delta r$ of the rotor is given by:

$$
\delta \tau=r(L \sin \varphi-D \cos \varphi) \delta r
$$

where $L$ and $D$ are the lift and drag forces per unit length along the blade, and $\varphi$ is the sum of the blade pitch angle and the angle of attack $\alpha$. From geometry and some manipulation, the axial and tangential induction factors are defined by: 


$$
\begin{gathered}
(1-a)=\lambda(\cos \varphi+\zeta \sin \varphi) / \sin ^{2} \varphi \\
a^{\prime} /\left(1+a^{\prime}\right)=\lambda(\sin \varphi-\zeta \cos \varphi) /(\sin \varphi \cos \varphi)
\end{gathered}
$$

where $\zeta=C_{D} / C_{L}$ is the lift to drag ratio and $\lambda=Z c C_{L} / 8 \pi r$ is the blade loading coefficient; $Z$ is the number of blades, $c$ is the blade chord length and $r$ is the local radius. The lift coefficient and drag coefficient are found from the angle of attack $\alpha$ using appropriate empirical or simulated aerofoil data. Equation 8 or 9 must be solved iteratively for one of the induction factors; the other induction factor can be found directly from its defining equation.

The actuator disc model, upon which the BEM code is based, breaks down when the axial induction factor exceeds a value of approximately 0.4 [22]. In this case an empirical model must be used to find $a$. First the thrust coefficient $C_{T}$ must be calculated:

$$
C_{T}=(1-a)\left(4 \lambda / \sin ^{2} \varphi\right)\left(C_{L} \cos \varphi+C_{D} \sin \varphi\right)
$$

The thrust coefficient, or axial force coefficient, is the non-dimensional axial force acting on the rotor. If $C_{T}$ $>0.96$ then the following empirical equation (from Anderson 1980 in [22]) is applied within the iteration procedure:

$$
a_{\text {new }}=\left(C_{T}-0.4256\right) / 1.3904
$$

This is derived from data from large heavily loaded turbines and therefore it is questionable whether it can be applied to a cm-scale device. However in the absence of an equivalent correlation for smaller devices it is a reasonable starting point.

A design-oriented BEM code was implemented in Matlab, using a relaxation factor to promote convergence of the iterative solution. This code solves for the local blade pitch angle $\beta$ based on the requirement of achieving the angle of attack that will maximise lift and minimise drag. Such an approach will yield pitch values which are optimised only for one specific rotor speed and free stream air speed, but the exercise can be repeated at many rotor speeds to discover, for a given air speed, the overall maximum energy extraction and the rotation speed at which this occurs. Using this approach, the power curves in Figure 3 were produced for families of rotors with optimised blade twist angles. In these plots each point on a given curve represents a different rotor design that has been optimised for the corresponding tip speed ratio. A chord length of 3 $\mathrm{mm}$, a span of $9.7 \mathrm{~mm}$, and a free stream speed of $5 \mathrm{~m} / \mathrm{s}$ were assumed throughout.

The BEM predictions in Figure 3 suggest that the highest shaft powers can be obtained at lower tip speed ratios and with higher blade counts, and this is consistent with classical wind mill theory when drag is taken into account [4]. With 12 blades the maximum predicted power at $U_{0}=5 \mathrm{~m} / \mathrm{s}$ is $5.2 \mathrm{~mW}$ and this occurs at $7,400 \mathrm{rpm}$, corresponding to $C_{p}=23 \%$ at $J=1.5$, while for 6 and 3 blades the maximum predicted powers are $4.1 \mathrm{~mW}$ at $10,000 \mathrm{rpm}\left(C_{p}=18 \%\right.$ at $\left.J=2\right)$ and $2.8 \mathrm{~mW}$ at $12,500 \mathrm{rpm}\left(C_{p}=12.4 \%\right.$ at $\left.J=2.5\right)$ 
respectively. The blade pitch angles corresponding to these optimum designs become progressively steeper as the blade number increases, consistent with a reduction in tip speed ratio. For example, the maximum and minimum pitch angles generated by the BEM code for the 3-blade design are $\beta=39.2^{\circ}$ and $\beta=14.1^{\circ}$, at radii of $3.5 \mathrm{~mm}$ and $9.7 \mathrm{~mm}$ respectively (corresponding to the hub and rim of the rotor), while the corresponding values for the 12 blade design are $\beta=43.3^{\circ}$ and $\beta=20.2^{\circ}$.

\subsection{Generator design}

The generator implemented in this work was a conventional 3-phase, AFPM machine [23] comprising a fixed stator coil located between two rotating rings of permanent magnets, as shown in Figure 4. The stator coil was implemented as a 4-layer flexible printed circuit board (PCB), while the magnet rings were formed by gluing cylindrical magnets into machined aluminium formers. The stator PCB was sandwiched between the two halves of the turbine casing (see Figure 1), while the magnet rings were mounted on the rim of the rotor. A $0.2 \mathrm{~mm}$-thick nickel ring was placed on the outer face of each magnet ring to act as a yoke or keeper.

Once the shroud outer diameter had been set at $3.2 \mathrm{~cm}$, the sizing of the generator was largely dictated by the proposed manufacturing route. Nevertheless, to assist in the design process a Matlab code was written that could provide estimates of the generator constant (voltage per unit rotation speed) and winding resistance as a function of the key design parameters. The primary aim was simply to realise a generator that could load the turbine sufficiently to produce turbine performance maps. However, with practical applications in mind, attention was also paid to maximising the generator constant as it is difficult to implement efficient power conditioning electronics for generators with very low output voltage.

Based on simulations, it was decided to use $2 \mathrm{~mm}$-diameter, $1 \mathrm{~mm}$-long NdFeB (neodymium-iron-boron) magnets (CERMAG grade $\mathrm{N} 40 \mathrm{H}$ ), placed at a radius of $12.5 \mathrm{~mm}$. The number of pole pairs was set at 16 which was slightly below the maximum number that could be accommodated (19) to ease manufacture of the magnet rings. The inner and outer radii of the stator coil were set at $11.6 \mathrm{~mm}$ and $14 \mathrm{~mm}$ respectively, and a design based on spiral coils was chosen because it gave higher output voltage in simulation than wavewound designs. The flexible PCB process (Stevenage Circuits Ltd, UK) had minimum track and gap widths of $80 \mu \mathrm{m}$ and $50 \mu \mathrm{m}$ respectively, and a minimum via pad diameter of $200 \mu \mathrm{m}$, and with these constraints a maximum of 5 turns could be accommodated in each spiral. The nominal track height was $20 \mu \mathrm{m}$.

Assuming a remanent flux density of $B_{r}=1.29 \mathrm{~T}$ for the magnets (as quoted by CERMAG), and a separation of $1.2 \mathrm{~mm}$ between the magnet rings (set by the rotor rim), the generator constant for each phase was predicted to be $235 \mu \mathrm{V} / \mathrm{rpm}$. The generator constant is defined here as the RMS open-circuit phase voltage (i.e. voltage across each individual winding) at unit rotation speed. The winding resistance per phase was estimated at $16.0 \Omega$, assuming the PCB tracks to be bulk copper with a resistivity of $1.69 \mu \Omega \mathrm{cm}$. With these values, the generator should be able to deliver an electrical power of $2.59 \mathrm{~mW}$ at $1,000 \mathrm{rpm}$ into a matched 
3-phase load. Alternatively, if operated as a single-phase generator, with the three windings connected in series so as to produce a source with twice the open-circuit voltage of a single winding, it should be able to deliver $1.15 \mathrm{~mW}$ at $1,000 \mathrm{rpm}$ into a matched load of $48 \Omega$. The prototype generator was found to have a generator constant of $215 \mu \mathrm{V} / \mathrm{rpm}$ which was very close to the predicted value. However, the winding resistance per phase was higher than expected, at around $25 \Omega$. This discrepancy was attributed to undercutting in the etch process used to manufacture the PCB, which led to narrowing of the copper tracks and also to additional resistance in the PCB vias which was not taken into account in the Matlab model. All the experiments reported here were performed with the generator configured for single-phase operation, and in this mode it could deliver a maximum power of $0.6 \mathrm{~mW} / \mathrm{krpm}^{2}$ into a matched load of $76.2 \Omega$.

\subsection{Fabrication.}

The turbine parts were fabricated by a combination of traditional machining and rapid prototyping. Referring to Figure 5, the rotor was assembled from a central hub, an annular rim, and a variable number of blades, all formed by rapid prototyping. A standard 3D printing process (Objet) with a resolution of around $50 \mu \mathrm{m}$ was used for the hub and rim, while a high resolution (ca $2 \mu \mathrm{m}$ laterally) stereolithography process (MicroTEC RMPD) was used for the blades to ensure accurate reproduction of the desired aerofoil profiles. Due to the nature of the latter process, it was necessary to fabricate the blades initially with constant pitch angle along their length, and then twist them prior to completion of the photocuring process in order to introduce the desired variation of pitch angle with radius. With this approach it was possible only to produce blades with a linear variation of pitch angle.

One batch of blades was manufactured, all with pitch angle varying from $36.5^{\circ}$ at the hub to $11.5^{\circ}$ at the rim. These values were based on a best fit to the BEM-derived pitch angle variation for an optimised 3-blade rotor. A NACA4406 aerofoil shape was used which was similar to the profile assumed in the BEM model (NACA4402), but thicker (6\% rather than $2 \%$ thickness) as there was a concern that thinner blades would be too fragile for handling. As fabricated the blades were highly flexible, so a $20 \mu \mathrm{m}$-thick electroplated nickel coating was applied to increase their rigidity. Several blades were glued to a polyurethane support and sputter coated from both sides with a conducting seed layer of copper (ca $200 \mathrm{~nm}$ thickness). Nickel plating was then carried out in a nickel sulphamate bath at a current density of $10 \mathrm{~mA} / \mathrm{cm}^{2}$. Figure $5 \mathrm{~b}$ shows an SEM image of an individual blade after nickel coating. To assemble each rotor, the required number of blades was glued to a hub and rim, using an alignment jig to ensure adequate mechanical balancing.

Referring to Figure 1, the turbine casing was fabricated as two identical machined parts. These were clamped together, either side of the PCB stator, with steel pins providing alignment. Early testing was carried out on a device with a stainless steel casing [12], but it was found that this first prototype had significant eddy current losses. The results presented here are for an improved device with a plastic (Tufset polyurethane) casing where eddy currents are greatly reduced. The rotor is supported by V-type jewel bearings (Bird Precision Inc. type RB82151 with $1 \mathrm{~mm}$-diameter pivot) which were selected for low friction. The bearings are 
screwed into metal inserts in the casing, allowing accurate axial positioning of the rotor with respect to the stator PCB, and fine adjustment of the bearing separation to obtain an acceptable compromise between friction and play. Figure 6 shows a photograph of an assembled 12-blade device with the inlet shroud and exit diffuser removed.

\section{Testing}

\subsection{Experimental methods}

Performance testing of the prototype turbine was carried out in an 18 " x 18 " wind tunnel facility designed for measurements at low wind speed. The device was mounted centrally in the tunnel, supported by a spar from one side as shown in Figure 7. The spar was hollow to provide a route for electrical connections to the generator from outside the tunnel, and its cross-section was profiled to minimise disturbance of the air stream. Wind speed was measured using a Pitot tube connected to a precision manometer (Furness Controls, type FCO510). The Pitot tube (also visible in Figure 7) was mounted just downstream of the turbine and about 4.5 " from the top of the tunnel.

Variable loading of the generator was achieved using the circuit in Figure 8 which allows adjustment of the load power under computer control. The generator, represented as a voltage source with a series winding resistance $R_{S}$, is connected in the feedback loop of an operational amplifier. The amplifier is configured for virtual earth operation, and a portion of the amplifier output voltage, derived by combining the amplifier output with a control voltage $k$ in an analogue multiplier, is fed back to the virtual earth input via a resistor $R_{F}$. With this configuration, the amplifier output is equal to the generator output voltage $V_{\text {gen }}$, while the current in the generator is $I_{g e n}=k V_{g e n} / R_{F}$. The electrical output power delivered by the generator, excluding the power dissipation in the winding resistance, is therefore given by $P_{\text {out }}=V_{\text {gen }} I_{\text {gen }}=k V_{\text {gen }}{ }^{2} / R_{F}$, while the power dissipated in $R_{S}$ is $P_{\text {res }}=I_{g e n}{ }^{2} R_{S}=k^{2} V_{\text {gen }}{ }^{2} R_{S} / R_{F}^{2}$. The sum of these two power levels represents the turbine shaft power after bearing losses and non-resistive generator losses. It also represents the total input power to the generator if non-resistive losses are neglected, and will be denoted $P_{\text {gen-in }}$.

It is helpful to express the above power levels in terms of the open-circuit generator voltage $V_{0}$ which, unlike $V_{\text {gen }}$, depends only on the rotational speed and not on loading. This leads to the following expressions:

$$
\begin{gathered}
P_{\text {gen-in }}=\frac{V_{0}^{2}}{R_{S}} \cdot \frac{\alpha}{1+\alpha} \\
P_{\text {out }}=\frac{P_{\text {gen-in }}}{(1+\alpha)}=\frac{V_{0}^{2}}{R_{S}} \cdot \frac{\alpha}{(1+\alpha)^{2}} \\
P_{\text {res }}=\frac{\alpha P_{\text {gen-in }}}{(1+\alpha)}=\frac{V_{0}^{2}}{R_{S}} \cdot \frac{\alpha^{2}}{(1+\alpha)^{2}}
\end{gathered}
$$


where $\alpha=k R_{S} / R_{F}$ represents the degree of loading. It can be seen that the total input power to the generator increases monotonically with $\alpha$, and hence $k$, approaching a limit of $V_{0}^{2} / R_{S}$ as $\alpha \rightarrow \infty$, at which point the generator output is effectively short-circuited. The electrical output power, on the other hand, passes through a maximum when $\alpha=1$, corresponding to matched loading of the generator. The electrical efficiency of the generator, $\eta_{e}=P_{\text {out }} / P_{\text {gen-in }}$, decreases monotonically as the loading is increased, and is $50 \%$ when $\alpha=1$. In the experiments reported here, $k$ could be varied over the range $0 \leq k \leq 1$, and $R_{F}$ was set at $10 \Omega$, so with $R_{S}$ $=76.2 \Omega$ the total load imposed by the generator could be varied from zero up to $88 \%$ of its limiting value.

In addition to wind tunnel testing, spin-down tests were carried out with a view to estimating the power losses in the bearings and their effect on the overall turbine efficiency. By differentiating the speed-time curves for the vacuum spin-down tests, the variations in bearing torque $T_{b}$ with speed could be obtained using the relation $T_{b}=-I \dot{\omega}$ where $I$ is the moment of inertia of the rotor. A value of $I=364 \mathrm{~g} \cdot \mathrm{mm} 2$ was used based on the geometry of the rotor and measured masses of the various constituent parts.

These tests were carried out with the turbine in a vacuum chamber in order to eliminate windage losses. In the absence of any air flow, the turbine was run up initially by operating the generator in reverse as a synchronous motor. This could be achieved simply by applying a negative control voltage to the circuit in Figure 8, since with $k<0$ this circuit injects power into the generator rather than loading it. An initial current impulse was applied to initiate rotation, and then the $k$ value was adjusted manually until stable operation at the desired initial speed was achieved. The drive was then cut off, and the variation of rotation speed over time was recorded by monitoring the open-circuit generator output. Using this data, and the moment of inertia of the rotor, the frictional torque and power loss were calculated as a function of rotation speed.

\subsection{Measured performance}

Figure 9 shows the measured variation of electrical output power with turbine rotation speed at different wind tunnel speeds in the range $3 \mathrm{~m} / \mathrm{s}$ to $10 \mathrm{~m} / \mathrm{s}$. These curves were obtained by setting the wind tunnel to a fixed speed, then varying the electrical loading on the generator through a series of steady state points. This in turn varies the turbine rotor speed and power output from point to point. In these experiments the rotation speed was intentionally limited to $4,000 \mathrm{rpm}$ in order to avoid vibration that had been observed at higher speeds due to slight mechanical imbalance in the rotor. It can be seen that for wind tunnel speeds up to $7 \mathrm{~m} / \mathrm{s}$ the measurements included the rotation speed corresponding to maximum output power, while for higher tunnel speeds this maximum power point could not be reached, and consequently the maximum power was limited by the maximum rotation speed. The maximum output power levels recorded ranged from $80 \mu \mathrm{W}$ at $3 \mathrm{~m} / \mathrm{s}$, to $2.5 \mathrm{~mW}$ at $7 \mathrm{~m} / \mathrm{s}$ and $4.3 \mathrm{~mW}$ at $10 \mathrm{~m} / \mathrm{s}$. The lowest tunnel speed for which the turbine would operate reliably, even when unloaded, was $3 \mathrm{~m} / \mathrm{s}$; below this point any slight fluctuation in the tunnel speed could cause it to stall. 
A notable feature of the curves in Figure 9 is that they intersect, with lower tunnel speeds yielding more electrical output power than higher ones over some speed ranges. This occurs because of the reduced electrical efficiency of the generator at higher loading levels. To illustrate this point, Figure 10 shows the variations of $P_{\text {gen-in }}$ with rotation speed for the same set of experiments. These plots show the turbine shaft power after bearing losses and non-resistive generator losses. It can be seen that the shaft power increases monotonically with wind speed.

Comparing Figures 9 and 10 it can be seen that the electrical efficiency of the generator is relatively low at high loading levels. For example, the highest recorded output power was $4.32 \mathrm{~mW}$ at a tunnel speed of 10 $\mathrm{m} / \mathrm{s}$ and a rotation speed of $3973 \mathrm{rpm}$. The resistive loss in the generator at this operating point was $5.81 \mathrm{~mW}$ implying an electrical efficiency of only $43 \%$. Higher electrical output powers could be obtained from the same turbine by improving the generator performance. For example a more advanced stator technology could be used that allows a higher copper fill factor, and hence lower winding resistance, such as that reported in [24]. It should also be noted that the wind tunnel experiments were conducted with only one magnet ring fitted (for ease of disassembly) and with the generator configured for single phase operation (to simplify the loading electronics), and both of these factors reduced the generator efficiency. The priority in this work was to characterise the turbine rather than to achieve the highest possible overall efficiency.

Figure 11a shows typical spin-down curves obtained both at atmospheric pressure and at a reduced pressure of 0.2 mbar. Eight curves from separate tests are shown overlaid for each pressure to give an idea of the uncertainty in the data. It can be seen that the spin-down time is consistently shorter at atmospheric pressure, and this is attributed primarily to windage although there may also be slightly higher bearing friction under these conditions due to the axial thrust on the upstream bearing caused by the pumping action of the rotor. It is also clear that the variability in the spin-down time is greater in the vacuum tests, and this may be because the bearing friction is less consistent when there is no axial thrust. The resulting torque-speed characteristics, obtained by differentiating the speed-time curves from the spin-down tests, are shown in Figure 11b (thin lines), together with a quadratic best-fit curve obtained by averaging the best-fits to the individual data sets (thick line). Also shown on this plot is the inferred power loss $P_{b}$ in the bearings, obtained from the best fit torque curve using the relation $P_{b}=T_{b} \omega$.

The quadratic term in the torque-speed characteristics is relatively small, contributing only about $4 \%$ of the torque at $4000 \mathrm{rpm}$. The bearing torque is therefore dominated by the constant and linear terms, and accordingly the variation of bearing power loss with rotation speed is approximately quadratic. This has important implications for the overall efficiency of the turbine at lower free stream flow speeds. For example, if the turbine is operated at constant tip speed ratio, the bearing loss will also be a quadratic function of the flow speed. Under these conditions, however, the turbine shaft power will scale as $P_{\text {shaft }} \propto$ $U_{0}{ }^{3}$ ignoring Reynolds number effects. The bearing loss will therefore become relatively more significant as the flow speed is reduced; it will also tend to lower the tip speed ratio at which the maximum output power is 
obtained. These features are evident in the experimental results. For example, at $U_{0}=3 \mathrm{~m} / \mathrm{s}, P_{\text {gen-in }}$ passes through a maximum of $90 \mu \mathrm{W}$ at a rotation speed of $780 \mathrm{rpm}$ (corresponding to $J=0.27$ ). At this rotation speed the bearing loss is about $150 \mu \mathrm{W}$, implying that $63 \%$ of the turbine shaft power is lost to the bearings. In contrast, at the higher flow speed of $U_{0}=7 \mathrm{~m} / \mathrm{s}, P_{\text {gen-in }}$ reaches a maximum of $3.26 \mathrm{~mW}$ at $3580 \mathrm{rpm}(J=$ 0.54). Here the bearing loss is about $1.48 \mathrm{~mW}$, so the bearings dissipate a more modest $31 \%$ of the shaft power.

The effects of bearing losses and resistive generator losses on the overall mechanical-to-electrical conversion efficiency are illustrated in Figure 12. This figure shows, for each different tunnel speed, the individual efficiencies $n_{b}=P_{\text {gen-in }} / P_{\text {shaft }}$ and $n_{e}=P_{\text {oul }} / P_{\text {gen-in }}$ at the point of maximum recorded output power. The shaft power is calculated as $P_{\text {shaft }}=\left(P_{\text {gen-in }}+P_{b}\right)$ where $P_{\text {gen-in }}$ is the experimentally measured input power to the generator (as shown in Figure 10) and $P_{b}$ is the estimated bearing power loss based on the best-fit torque curve (Figure 11b). $P_{\text {shaft }}$ therefore represents the available shaft power after non-resistive generator losses. It can be seen that the bearing efficiency rises with increasing flow speed, while the generator efficiency falls, and the combined effect is to produce a single maximum in the overall conversion efficiency $\eta=\eta_{\mathrm{b}} \eta_{\mathrm{e}}$.

\section{Discussion}

Turbine performance data is typically presented in the form of a normalised plot showing the power coefficient as a function of tip speed ratio as this removes the main scaling effects of size and flow speed. Figure 13 shows performance curves of this type for the prototype turbine presented here. When calculating the power coefficient, the shaft power was again taken to be $P_{\text {shaft }}=\left(P_{\text {gen-in }}+P_{b}\right)$, while the area used was that of the rotor. It can be seen that the normalised turbine performance is largely independent of the free stream flow speed, as expected for a given turbine design over a relatively narrow range of flow speeds, where Reynolds numbers do not vary widely. The performance curve normally has a single turning point corresponding to a maximum $C_{p}$, and this can be observed for the intermediate flow speeds of 5 and $6 \mathrm{~m} / \mathrm{s}$. In both cases a maximum value of $C_{p} \sim 0.09$ is reached at $\mathrm{J} \sim 0.6$. The turning points could not be reached at lower flow speeds because of bearing losses, or at higher flow speeds because of the limited maximum rotation speed in the experiments.

Also shown in Figure 13 is a BEM model prediction of the variation of $C_{p}$ with $J$ for a 12-blade rotor with the particular blade design that was fabricated. Additional aerofoil data was required at higher angles of attack in order to predict turbine performance over the required range of rotation speeds. Kesel [25] measured lift and drag at $R e_{c}=10,000$ on a range of aerofoil profiles including flat and curved plates and dragonfly wing profiles, for angles of attack up to 40 degrees, and data from [25] was combined with data from Kunz in order to predict turbine performance across a wider range. Although Kesel's data was for higher $R e_{c}$ and for different aerofoil shapes, it was the most appropriate available data over the required range of angles of attack. 
The agreement between the BEM prediction and the experimental results is good considering the simplicity of the model used. No attempt was made to model the implications of swirl in the wake behind the turbine, or of the effect of the shroud or duct around the rotor. The shroud significantly changes the fluid flow through the turbine, but the influence is difficult to predict using simple methods because of the coupled interaction between turbine loading and the duct shape. For large wind turbines ducts are ruled out because of the prohibitive cost of what would be a massive structure that can withstand extreme winds and also adjust to off-axis flow; instead it is cheaper to build a larger rotor to increase power output. However, at smaller scales a duct with a diffuser can enhance performance by recovering kinetic energy downstream of the rotor. Lawn [26] estimates that for maximum power extraction from a given turbine area, a well designed duct and low resistance turbine should give about a $30 \%$ enhancement in power extraction over the free stream case. However there is a complex interaction between the rotor design and the duct aerodynamics [27], the investigation of which was beyond the scope of this work. Here we simply note that ignoring the effect of the shroud might be expected to result in under-estimation of the turbine performance. On the other hand, the use of higher lift and drag data obtained at higher Reynolds number would be expected to have the opposite effect.

Table 1 summarises the overall performance at flow speeds in the range 3 to $7 \mathrm{~m} / \mathrm{s}$ where the maximum peak of the performance curve could be reached. Table 1a shows the maximum recorded electrical output power at each flow speed, along with the corresponding resistive generator loss, estimated bearing loss, and estimated turbine shaft power. In Table $1 \mathrm{~b}$ the overall efficiency is broken down in to a power coefficient and individual efficiencies associated with the bearing $\left(\eta_{b}\right)$ and resistive generator losses $\left(\eta_{e}\right)$. The previously noted upward and downward trends in the bearing and generator efficiencies with increasing flow speed are clearly demonstrated. It is noted that the power coefficients are somewhat lower than the peak values shown in Figure 13. This is mainly because they are calculated using the entire device cross-sectional area including the shroud, but also because the peaks in the electrical output power occur at tip speed ratios that are nonoptimal for the turbine.

Figure 14 compares the performances of the various airflow-driven harvesters reported in the literature with that of the device presented here. For each device, the maximum quoted electrical output power density (power per unit cross-sectional area) is plotted against free stream flow speed. Also shown are lines representing overall efficiencies of 0.593, 0.1 and 0.0025, corresponding to the Betz limit and to the best and worst performing turbine-based devices. In all cases the power density is based on the entire device crosssection presented to the air flow as this makes for the fairest comparison. It can be seen that up to now turbine-based devices (filled symbols) have generally shown better performance than non-turbine designs (open symbols). The device presented in this paper has lower overall efficiency than most of the other turbine harvesters, but this is to be expected because of its smaller size and hence lower Reynolds number operation. Comparing with the device reported in [4], which is closest in size and $74 \%$ larger in area, the 
performance is similar at flow speeds around $5 \mathrm{~m} / \mathrm{s}$. The device reported here performs less well at higher flow speeds primarily because of generator losses, and also because of the rotation speed limit imposed during wind tunnel tests. The minimum operating speed of $3 \mathrm{~m} / \mathrm{s}$ is lower than reported in [4]. The bestperforming non-turbine harvester [9] has similar performance at low flow speeds but is significantly larger (6.5× larger cross-section).

\section{Conclusions}

The device presented in this paper is, to the authors' knowledge, the smallest turbine-based energy harvester reported to date. Aimed specifically at duct monitoring applications, it can operate at flow speeds down to 3 $\mathrm{m} / \mathrm{s}$ and deliver between $80 \mu \mathrm{W}$ and $2.5 \mathrm{~mW}$ of electrical power at flow speeds in the range $3 \mathrm{~m} / \mathrm{s}$ to $7 \mathrm{~m} / \mathrm{s}$ which are typical of an air conditioning duct. Wind tunnel experiments and spin-down tests have shown that the achievable overall efficiency is limited mainly by bearing loss at low flow speeds and by resistive generator loss at high flow speeds when the generator has to be heavily loaded to keep the turbine rotation speed within allowable limits. Future work will be aimed at addressing these issues. Further turbine design work will also be carried out taking into account bearing losses, as this will lead to a rotor design optimised for working at lower tip speed ratios.

\section{Acknowledgements}

The authors are grateful to colleagues in the Department of Aeronautics, Imperial College London for their assistance with this work, in particular Joanna Whelan for help with the development of the BEM code, Nigel MacCarthy and Anthony Oxlade for assistance with wind tunnel testing, and Michael Graham for helpful discussions on aspects of wind turbine theory. This work was funded in part by the UK Engineering and Physical Sciences Research Council, Grant No. GR/S67135/01, "Platform support for 3D electrical MEMS".

\section{References}

1. Douglas J. et al., "Fluid mechanics", Harlow: Pearson Prentice Hall, $5^{\text {th }}$ Edition, 2005.

2. CIBSE, CIBSE Concise Handbook, Armstrong J. (Ed), London: The Chartered Institution of Building Services Engineers, 2008.

3. Federspiel C.C., Chen J., "Air-powered sensor”, Proc. IEEE Sensors 2003, vol. 1, pp. 22-25, 2003.

4. Rancourt D., Tabesh A., Fréchette L.G., "Evaluation of centimeter-scale micro wind mills: aerodynamics and electromagnetic power generation", Proc. PowerMEMS 2007, pp. 93-96, 2007.

5. Myers R., Vickers M., Kim H., Priya S.,’Small scale windmill”, Appl. Phys. Lett., vol. 90, paper 054106, 2007.

6. Xu F.J., Yuan F.G., Hu J.Z., Qiu Y.P., "Design of a miniature wind turbine for powering wireless sensors", Proc. SPIE vol. 7646, paper 764741-1, 2010. 
7. Carli, D., Brunelli D., Bertozzi D., Benini L., "A high-efficiency wind-flow energy harvester using micro turbine", Proc. Int. Symp. on Power Electronics Electrical Drives, Automation and Motion, SPEEDAM 2010, pp. 778-783, 2010.

8. $\quad$ uicroWindbelt data sheet, Humdinger Wind Energy LLC, 2008.

9. Zhu, D., Beeby, S., Tudor, J., White, N., Harris, N., "A novel miniature wind generator for wireless sensing applications", Proc. IEEE Sensors 2010, pp. 1415-1418, 2010.

10. Pobering S., Schwesinger N., "Power supply for wireless sensor system", Proc. IEEE Sensors 2008, pp. 685-688, 2008.

11. St Clair D., Bibo A., Sennakesavababu V.R., Daqaq M.F., Li G., "A scalable concept for micropower generation using flow-induced self-excited oscillations", Appl. Phys. Lett., vol. 96, 144103 (3 pp.), 2010.

12. Bansal A., Howey D.A., Holmes A.S., "Cm-scale air turbine and generator for energy harvesting from low-speed flows" Proc. Transducers 2009, pp. 529-532, 2009.

13. Holmes A.S., Howey D.A., Bansal A., Yates D.C., "Self-powered wireless sensor for duct monitoring", Proc. PowerMEMS 2010, Poster Proceedings, pp. 115-118, 2010.

14. Holmes A.S., Hong G., Pullen K.R., "Axial-flux permanent magnet machines for micropower generation", J. Microelectromech. Syst., vol. 14, no. 1, pp. 54-62, 2005.

15. Holmes A.S., Hong G., Pullen K.R., Buffard K.R., "Axial-flow microturbine with electromagnetic generator: design, CFD simulation and prototype demonstration", Proc. MEMS 2004, $17^{\text {th }}$ IEEE Int. Conf. on MEMS, Maastricht, The Netherlands, 25-29 Jan 2004, pp. 568-571, 2004.

16. Kunz P., Kroo I., "Analysis, design and testing of airfoils for use at ultra- low Reynolds numbers", in Fixed and Flapping Wing Aerodynamics for Micro Air Vehicle Applications, T.J. Mueller (Ed), AIAA, 2001.

17. Lissaman P., "Low-Reynolds-number airfoils", Annual Review of Fluid Mechanics, vol. 15, no. 1, pp. 223-239, 1983.

18. Kunz P., "Aerodynamics and design for ultra-low Reynolds number flight”, PhD Thesis, Department of Aeronautics and Astronautics, Stanford University, 2003.

19. Du Z., Selig M., "The effect of rotation on the boundary layer of a wind turbine blade", Renewable Energy, vol. 20, no. 2, pp. 167-181, 2000.

20. Chaviaropoulos P.K., Hansen M.O.L., "Investigating three-dimensional and rotational effects on wind turbine blades by means of a quasi-3D Navier-Stokes solver", J. Fluids Engineering, vol. 122, pp. 330$336,2000$.

21. Kunz P., Strawn R., "Analysis and design of rotors at ultra-low Reynolds numbers", AIAA 2002-0099, 2002.

22. Dixon S., "Fluid mechanics and thermodynamics of turbomachinery", Amsterdam: Elsevier, $5^{\text {th }}$ ed., 2005.

23. Geiras G.F., Wang R.J., Kamper M.J., “Axial flux permanent macgnet brushless machines”, Springer, $2^{\text {nd }}$ ed., 2008.

24. Herrault F., Yorish S., Crittenden T., Allen M.G., "Microfabricated, ultra-dense, three-dimensional metal coils", Proc. Transducers 2009, pp. $1718-1721,2009$.

25. Kesel A.B., "Aerodynamic characteristics of dragonfly wing sections compared with technical aerofoils", J. Experimental Biology, vol. 203, no. 20, pp. 3125-3135, 2000.

26. Lawn C.J., "Optimization of the power output from ducted turbines", Proc. Inst. Mech. Engineers, Part A: Journal of Power and Energy, vol. 217, no. 1, pp. 107-117, 2003.

27. Jamieson P., "Generalized limits for energy extraction in a linear constant velocity flow field", Wind Energy, vol. 11, pp. 445-457, 2008. 


\section{TABLES}

Table 1a

\begin{tabular}{|ccccc|}
\hline $\begin{array}{c}\boldsymbol{U}_{\mathbf{0}} \\
(\mathbf{m} / \mathbf{s})\end{array}$ & $\begin{array}{c}\text { Shaft power } \\
\boldsymbol{P}(\mathbf{m W})\end{array}$ & $\begin{array}{c}\text { Bearing loss } \\
\boldsymbol{P}_{\boldsymbol{b}}(\mathbf{m W})\end{array}$ & $\begin{array}{c}\text { Generator loss } \\
\boldsymbol{P}_{\text {res }}(\mathbf{m W})\end{array}$ & $\begin{array}{c}\max \left\{\boldsymbol{P}_{\text {out }}\right\} \\
(\mathbf{m W})\end{array}$ \\
\hline 3 & 0.32 & 0.23 & 0.006 & 0.079 \\
4 & 0.93 & 0.61 & 0.021 & 0.30 \\
5 & 1.78 & 0.84 & 0.12 & 0.81 \\
6 & 3.10 & 1.16 & 0.36 & 1.58 \\
7 & 4.74 & 1.48 & 0.77 & 2.49 \\
\hline
\end{tabular}

Table 1b

\begin{tabular}{|c|c|c|c|c|}
\hline $\begin{array}{c}U_{0} \\
(\mathrm{~m} / \mathbf{s})\end{array}$ & $\begin{array}{c}\begin{array}{c}\text { Power } \\
\text { coefficient }\end{array} \\
C_{p_{-} \text {shroud }}(\%)\end{array}$ & $\begin{array}{c}\begin{array}{c}\text { Bearing } \\
\text { efficiency }\end{array} \\
\eta_{b}(\%)\end{array}$ & $\begin{array}{c}\text { Generator } \\
\text { efficiency } \\
\eta_{e}(\%)\end{array}$ & $\begin{array}{c}\begin{array}{c}\text { Overall } \\
\text { efficiency }\end{array} \\
(\%)\end{array}$ \\
\hline 3 & 2.42 & 27.0 & 92.9 & 0.61 \\
\hline 4 & 3.01 & 34.2 & 93.4 & 0.96 \\
\hline 5 & 2.94 & 52.5 & 87.2 & 1.35 \\
\hline 6 & 2.97 & 62.7 & 81.5 & 1.52 \\
\hline 7 & 2.86 & 68.8 & 76.3 & 1.50 \\
\hline
\end{tabular}




\section{FIGURES}

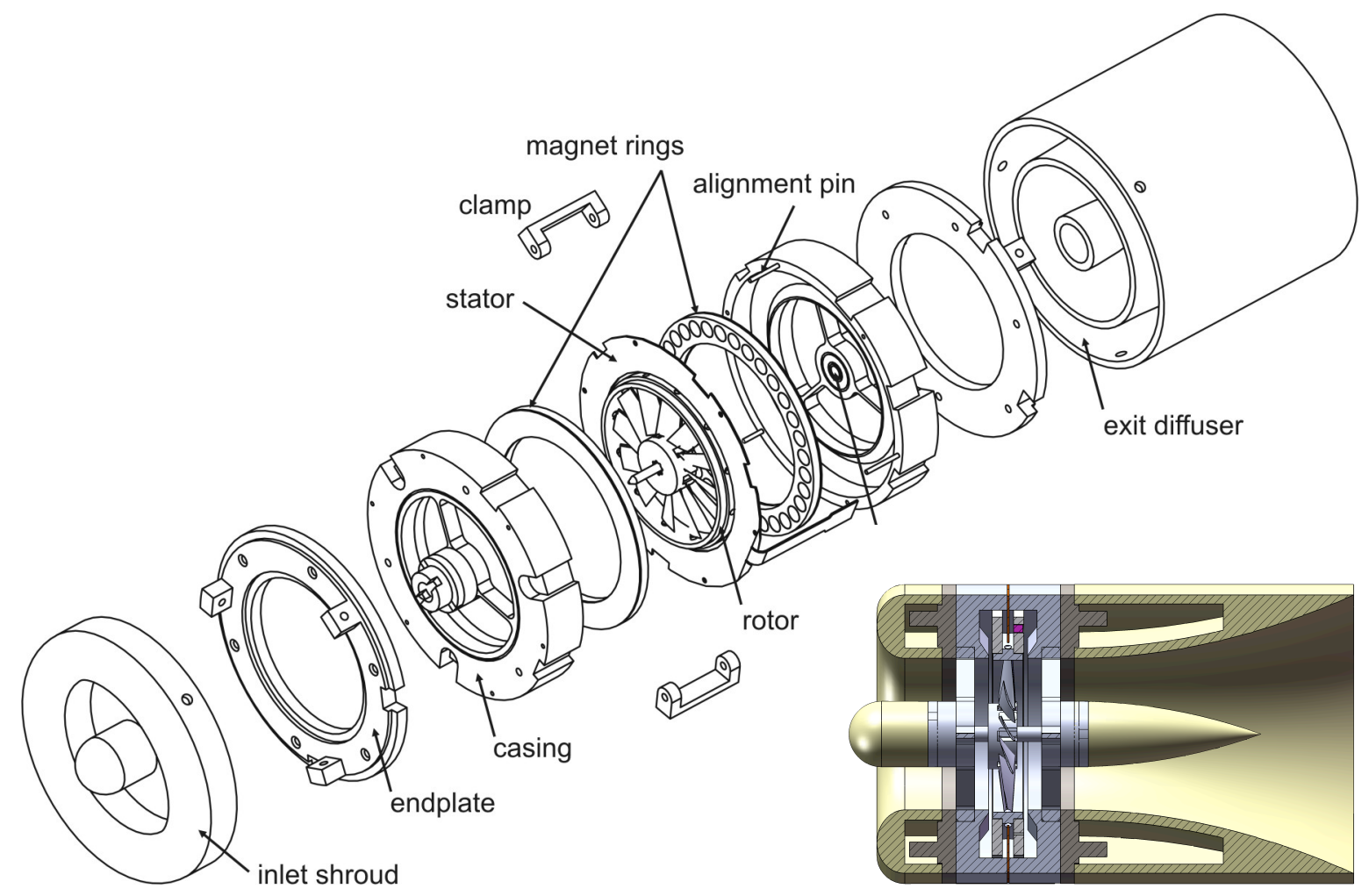

(a)

(b)

Figure 1: Schematics of overall device showing (a) exploded and (b) cut-away views.

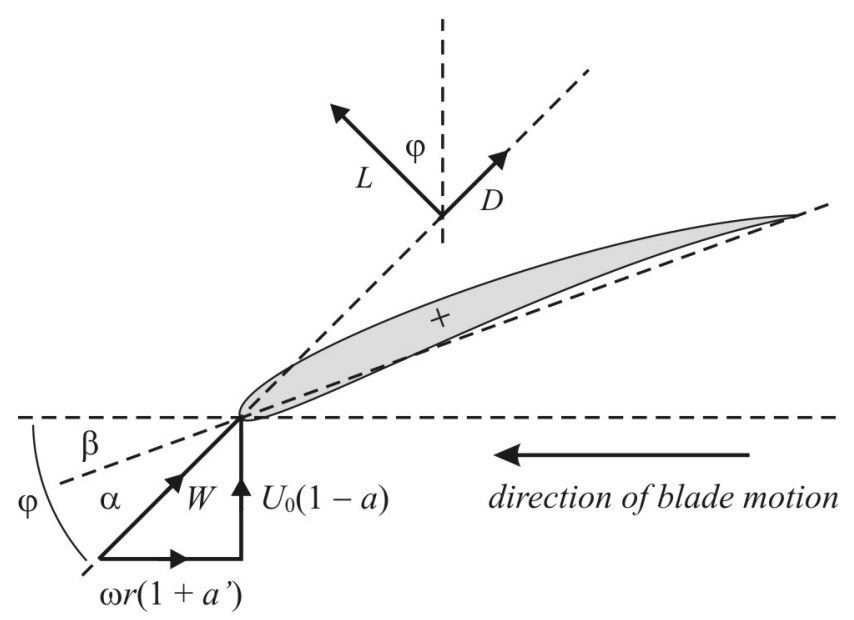

Figure 2: Blade section as modelled in BEM method, showing leading edge velocity triangle and lift and drag forces (shown above the blade for clarity). $W$ is the velocity of the incoming flow relative to the turbine blade. 

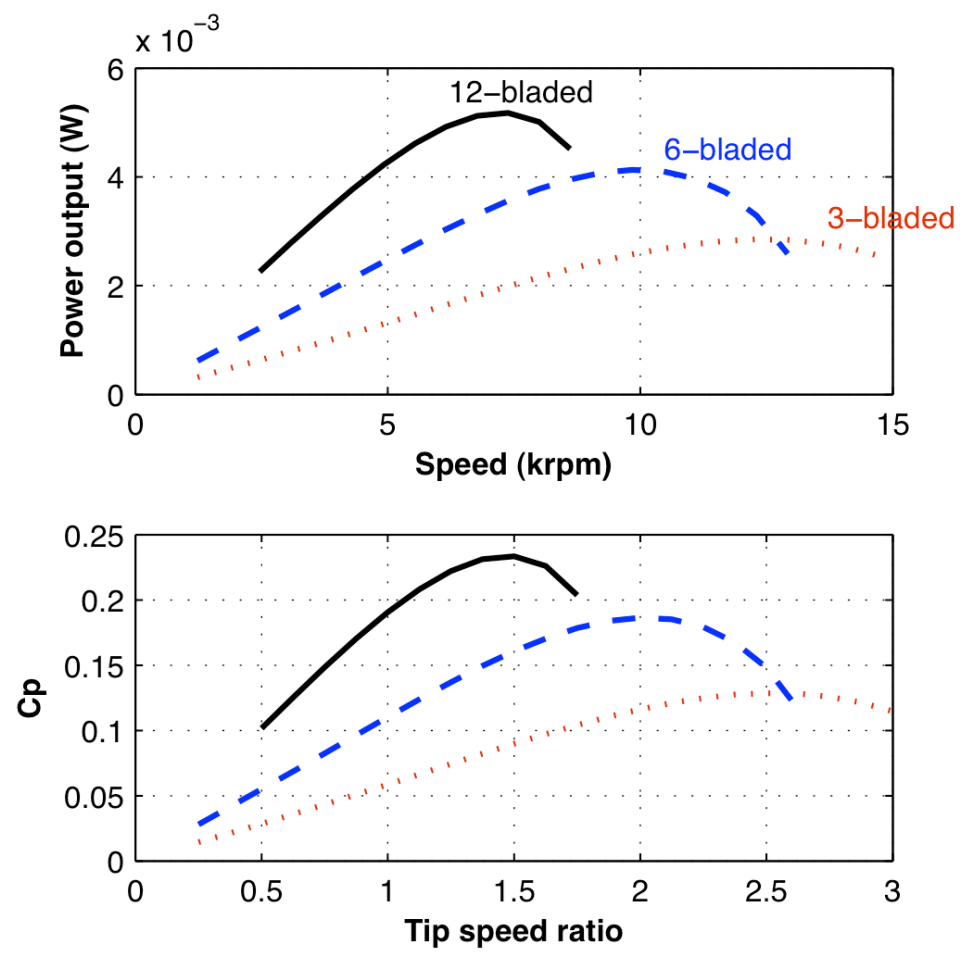

Figure 3: Variations of output power with shaft speed, and $\mathrm{Cp}$ with tip speed ratio, for families of optimized 3-, 6- and 12-blade rotors, as predicted by BEM model. A free-stream speed of $U_{0}=5 \mathrm{~m} / \mathrm{s}$ is assumed throughout.

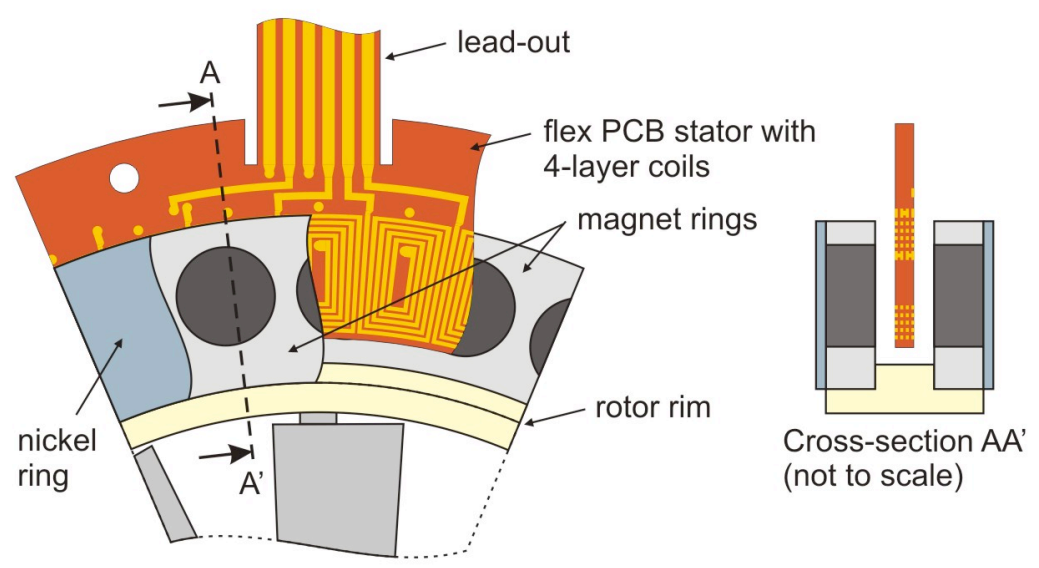

Figure 4: Schematic showing construction of permanent magnet generator. (a) Plan view, cut away to show magnet rings and stator PCB; (b) cross-section along AA'. 


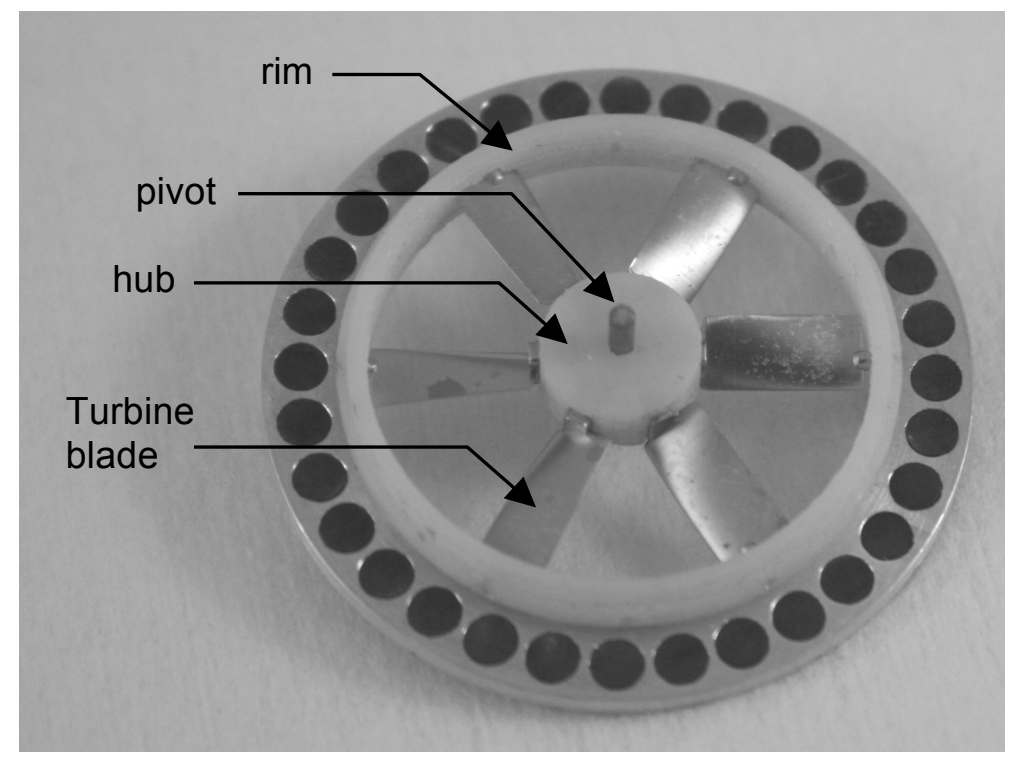

(a)

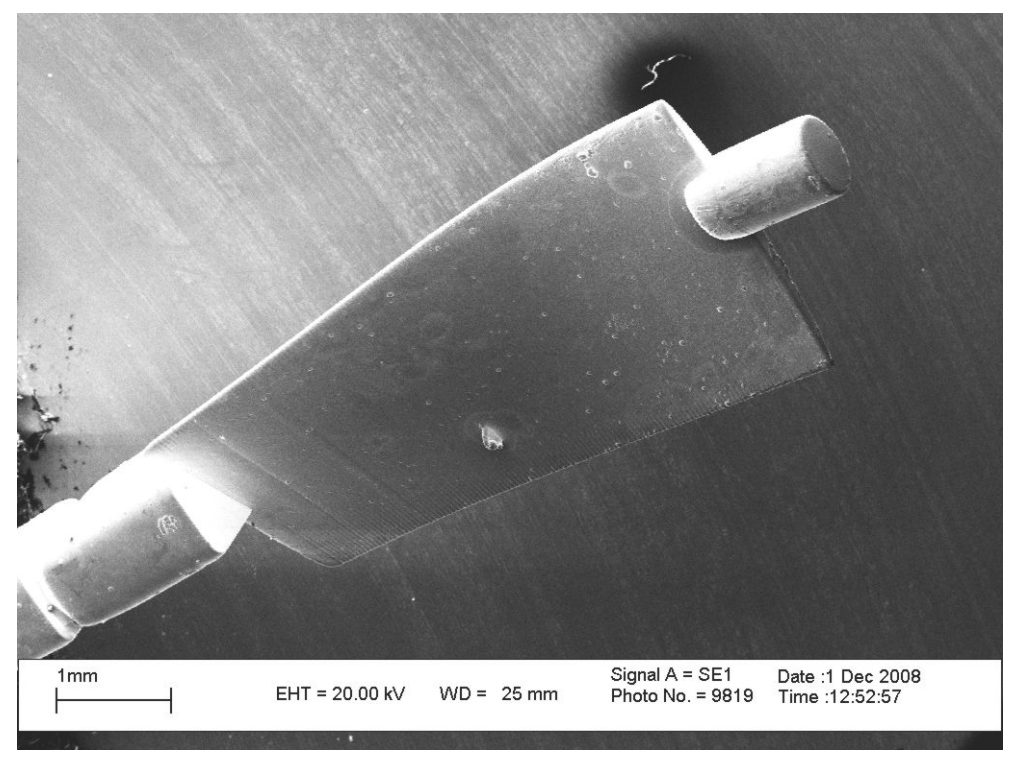

(b)

Figure 5: (a) Photograph of assembled 6-blade rotor with one magnet ring fitted; (b) SEM image showing rapid-prototyped turbine blade after nickel coating. 


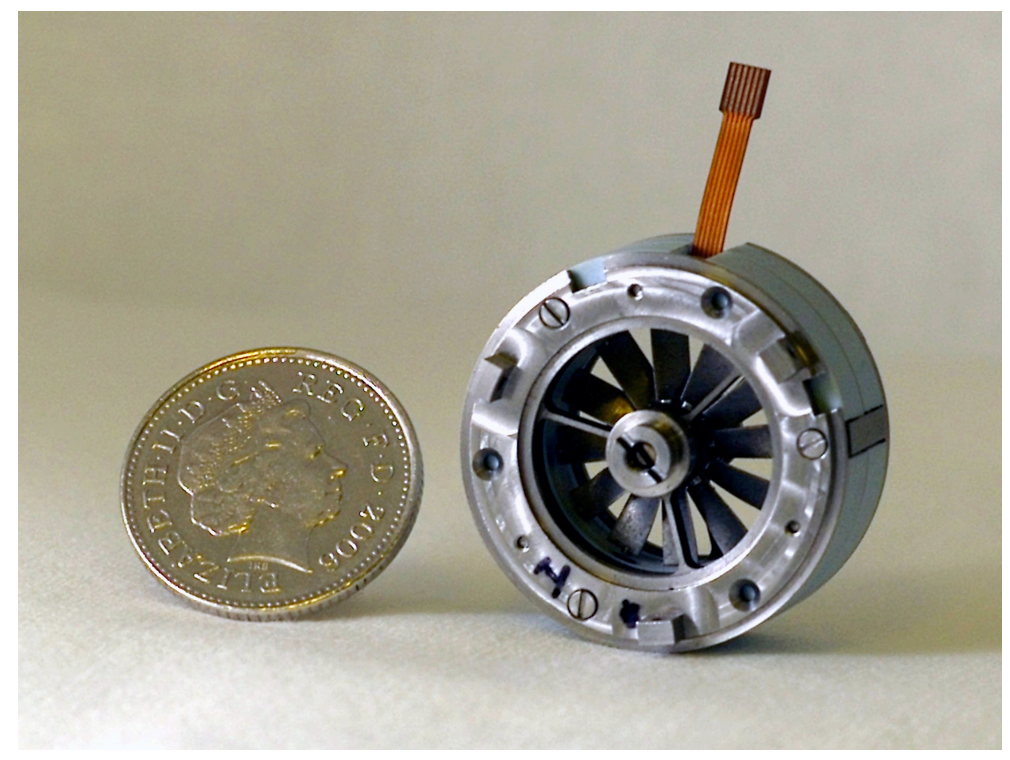

Figure 6: Assembled 12-blade turbine with inlet shroud and exit diffuser removed, next to $£ 1$ coin for scale.

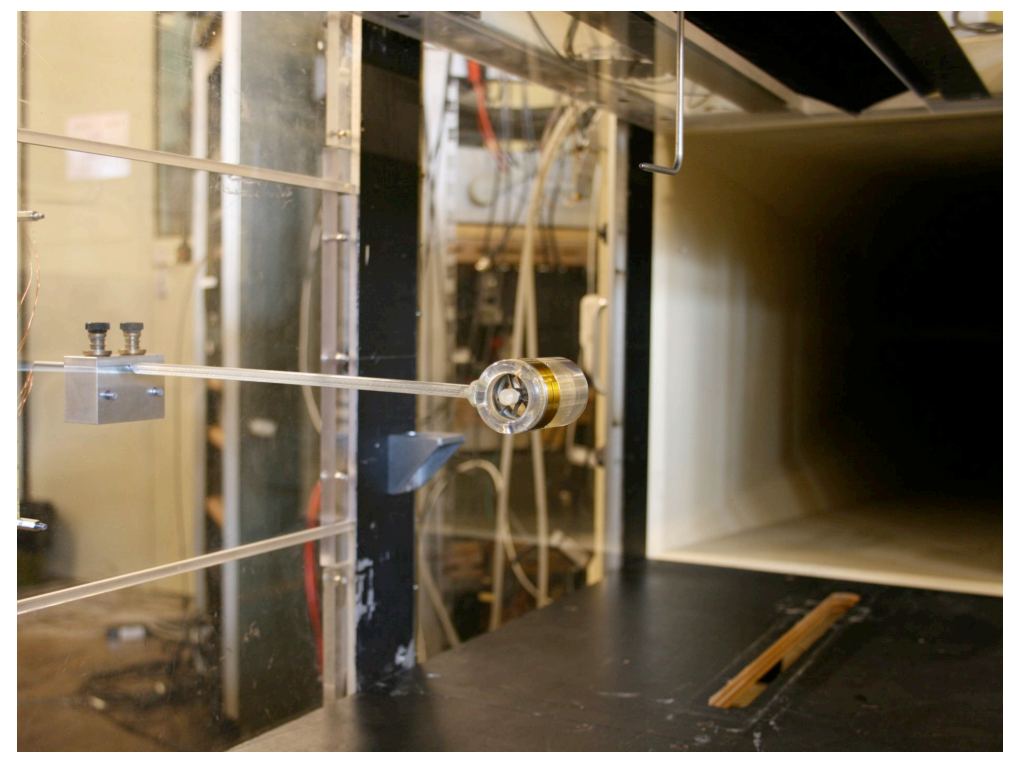

Figure 7: Experimental section of 18" x 18" wind tunnel, with turbine mounted for testing. Pitot tube for tunnel speed measurement is visible at the top of the image 


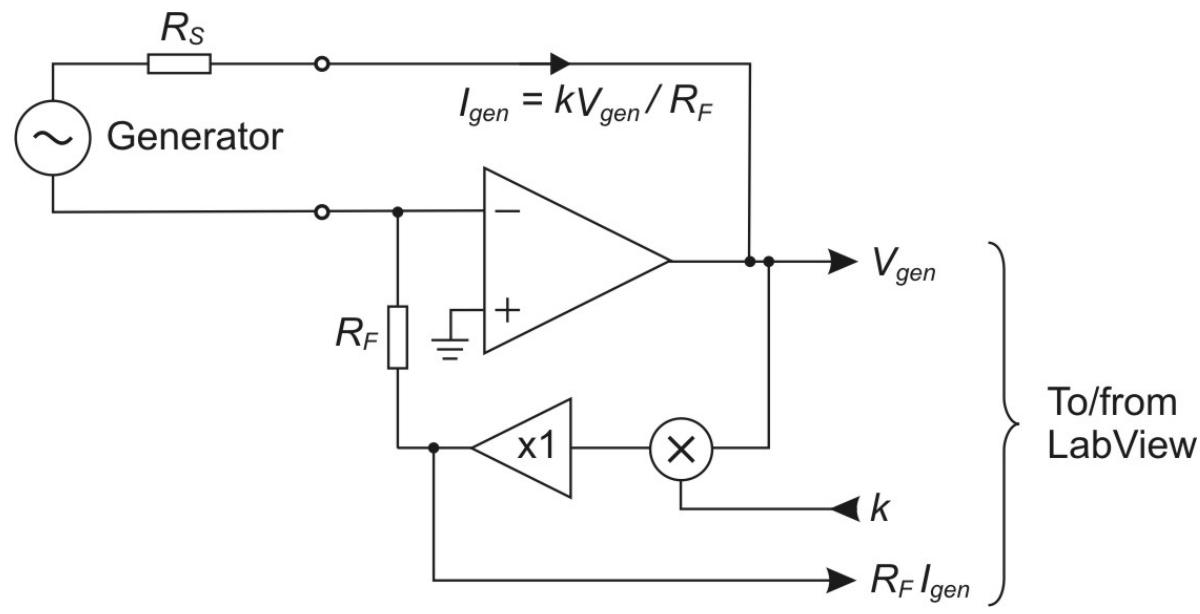

Figure 8: Circuit used to apply known load to generator during performance testing $(\mathrm{k}>0)$, and to drive generator as synchronous motor during spin-down tests $(\mathrm{k}<0)$.

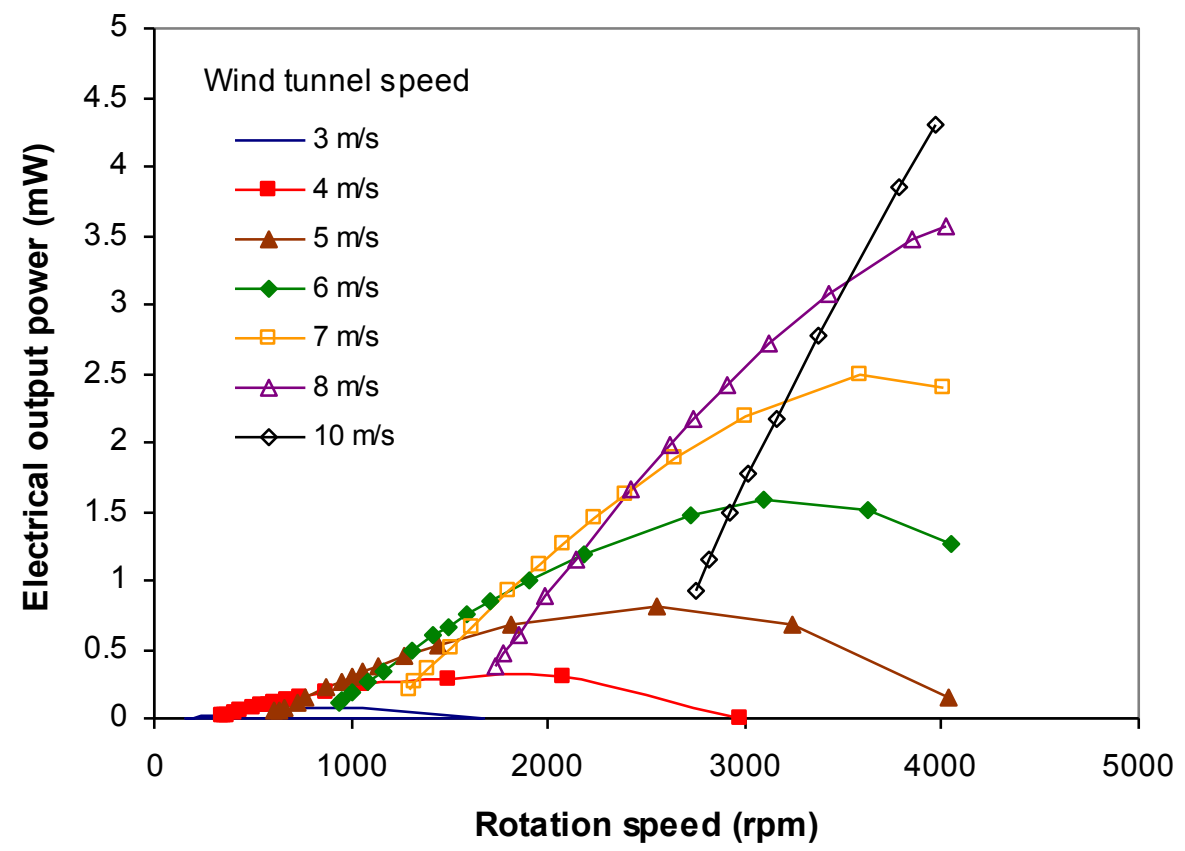

Figure 9: Measured performance curves for turbine and generator combination, showing variation of electrical output power with rotation speed for different wind tunnel speeds. 


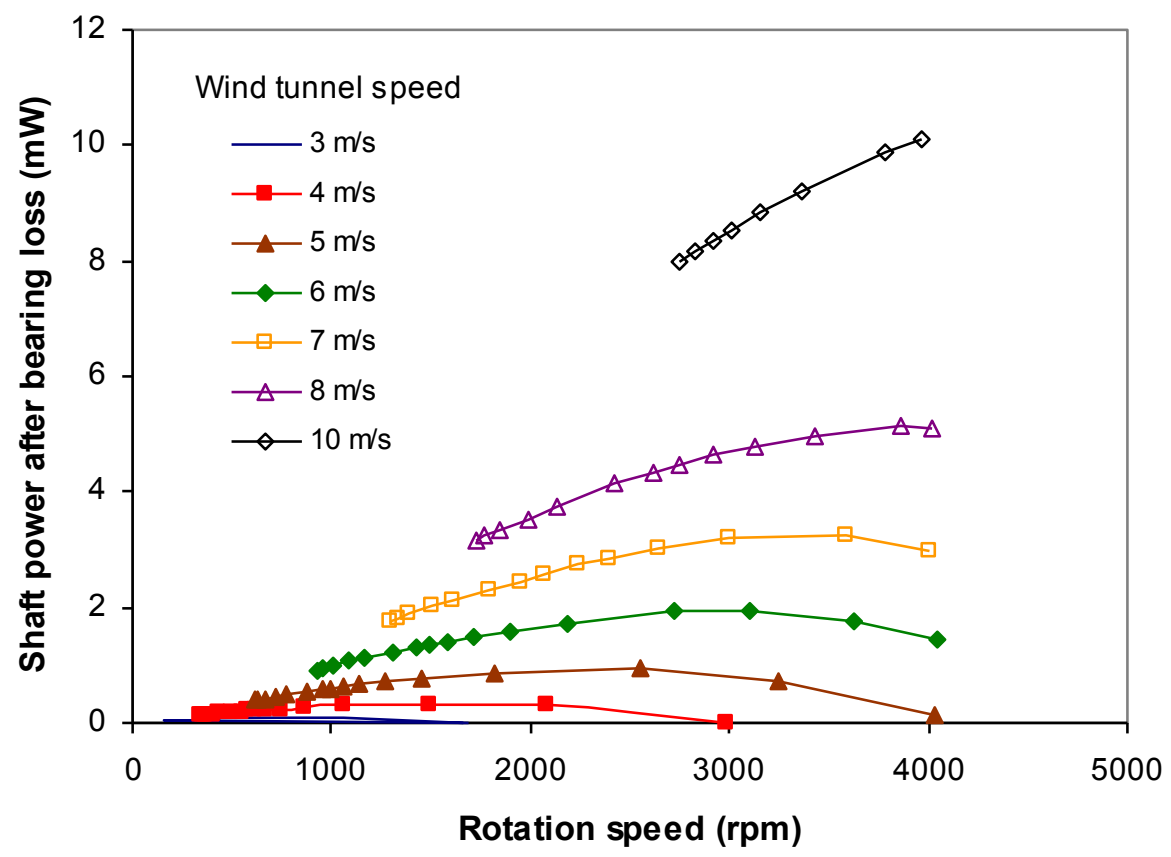

Figure 10: Turbine performance curves, showing variation of turbine shaft power with rotation speed for different wind tunnel speeds. Curves show available shaft power after bearing losses and non-resistive generator losses, but before resistive generator losses. 


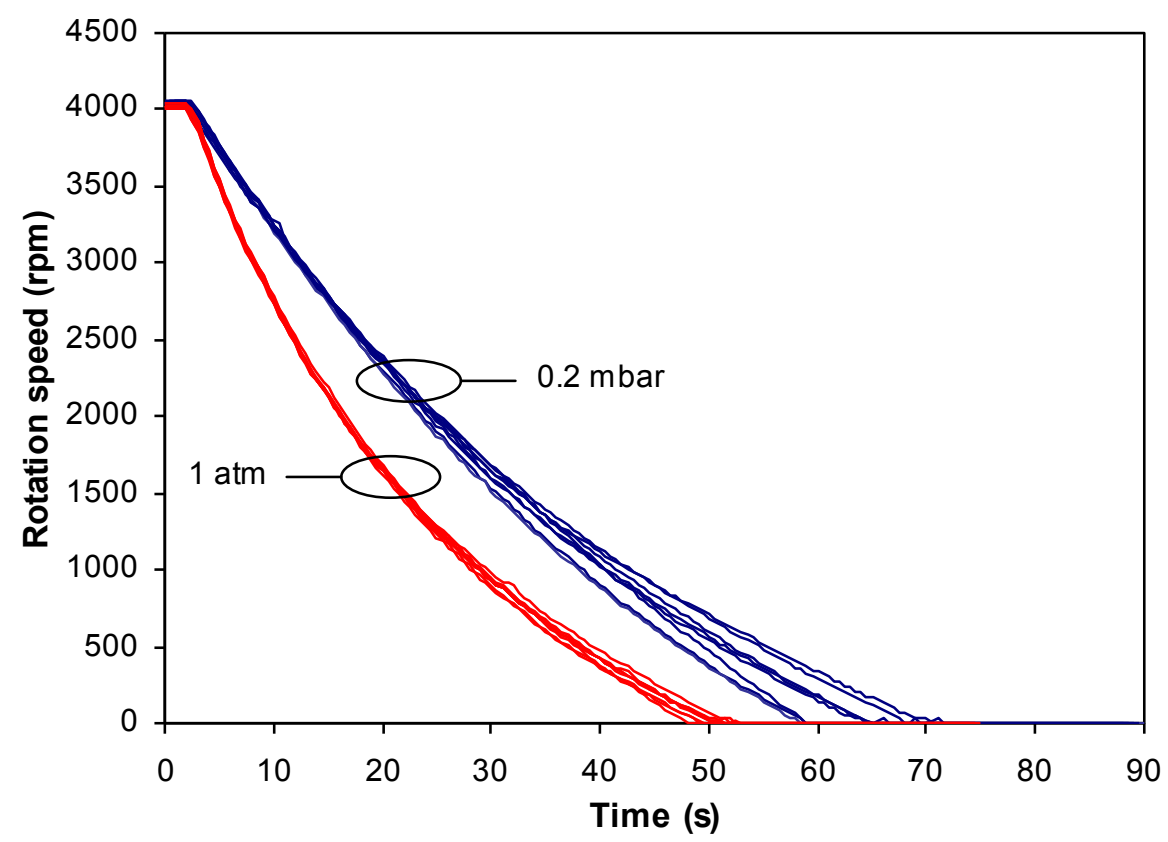

(a)

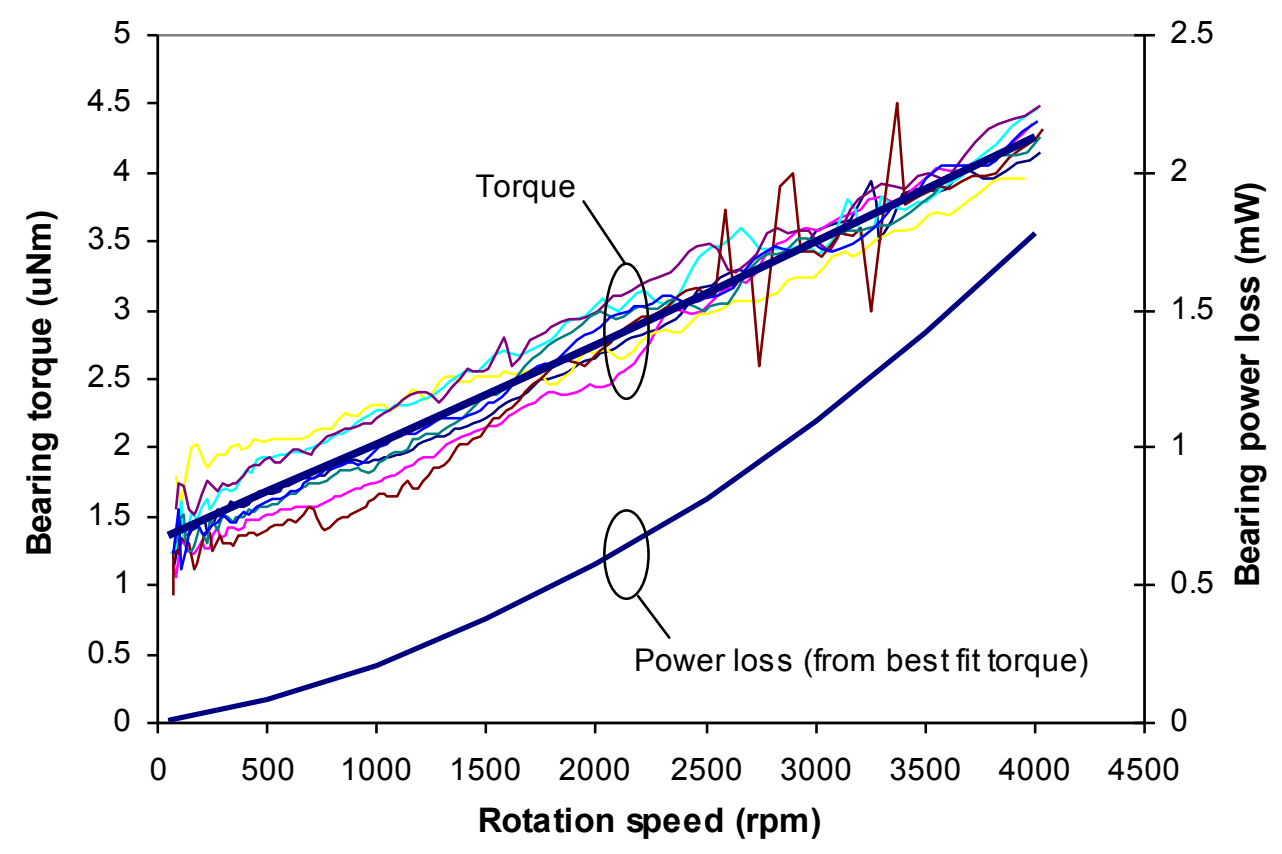

(b)

Figure 11: (a) Measured variations of rotation speed with time for spin-down tests carried out at atmospheric pressure and at $0.2 \mathrm{mbar}$; (b) bearing torque and power loss as a function of rotation speed, inferred from low-pressure spin-down tests. Power loss curve is derived from best fit torque curve (thick line). 


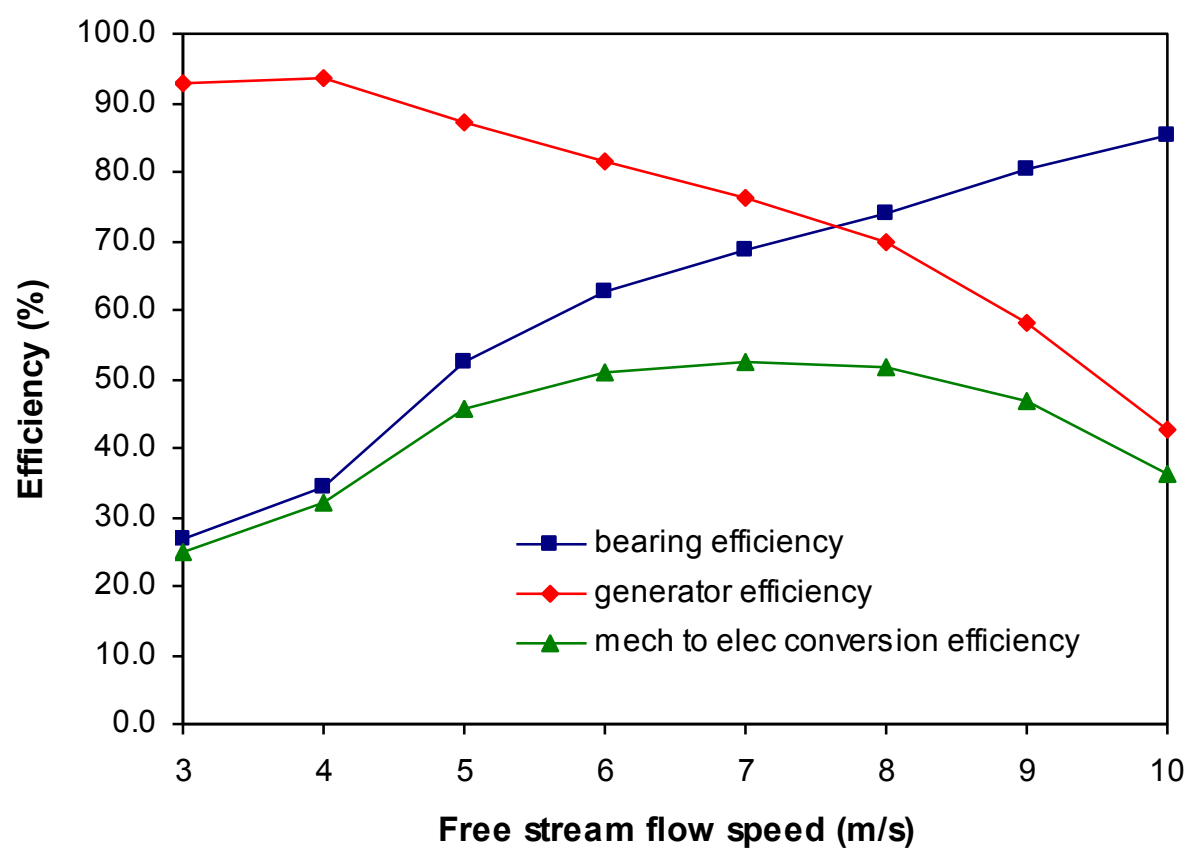

Figure 12: Variations with free stream flow speed of bearing efficiency $\eta_{b}$, generator efficiency $\eta_{\mathrm{e}}$ and overall mechanical-to-electrical conversion efficiency $\eta=\eta_{b} \eta_{\mathrm{e}}$ at point of maximum output power. 

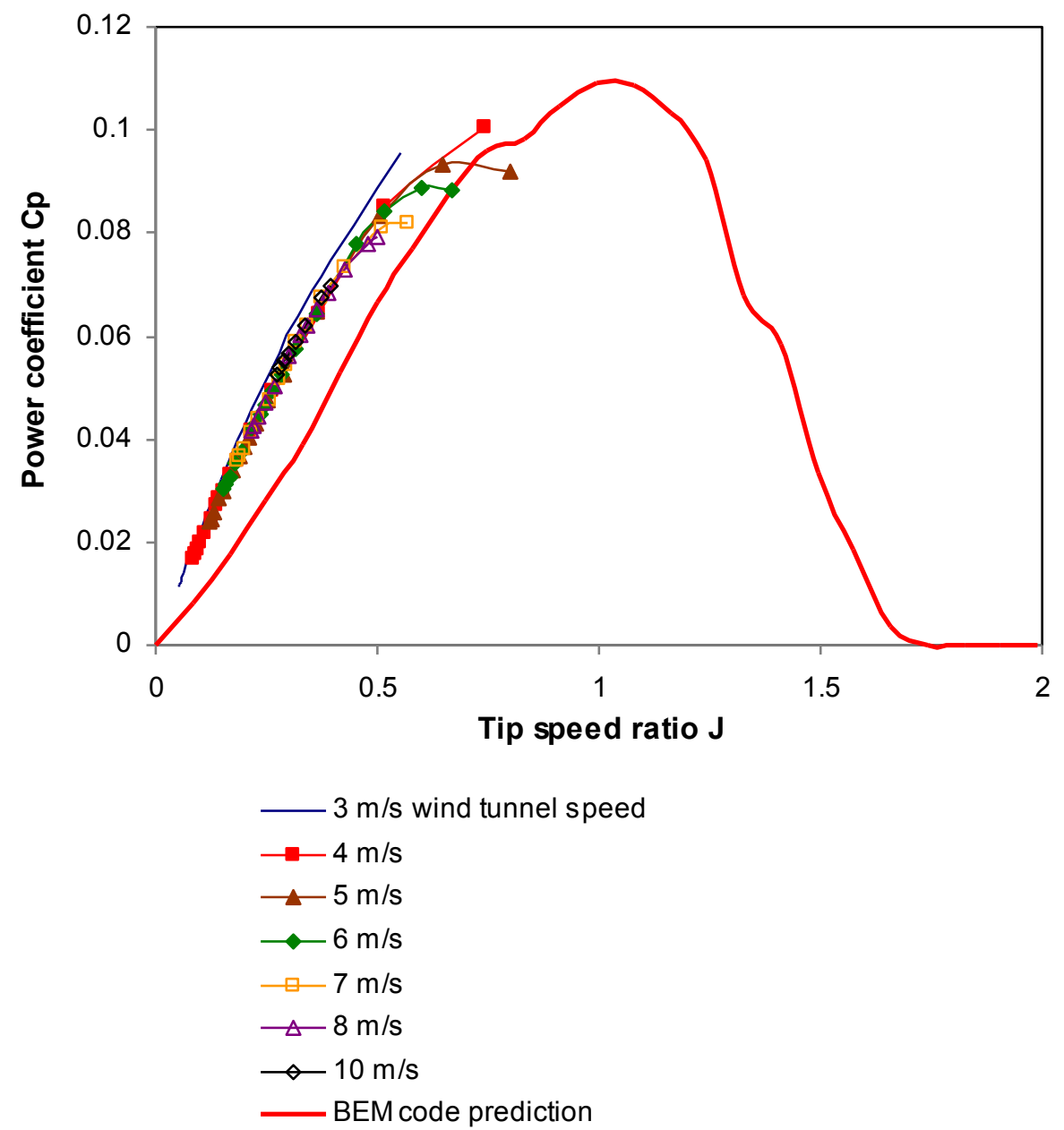

Figure 13: Normalised turbine performance curves showing $C_{p}$ vs $J$ at different wind tunnel speeds and comparison with BEM model predictions (thick line). Power coefficients are based on estimated turbine shaft power before bearing losses. 


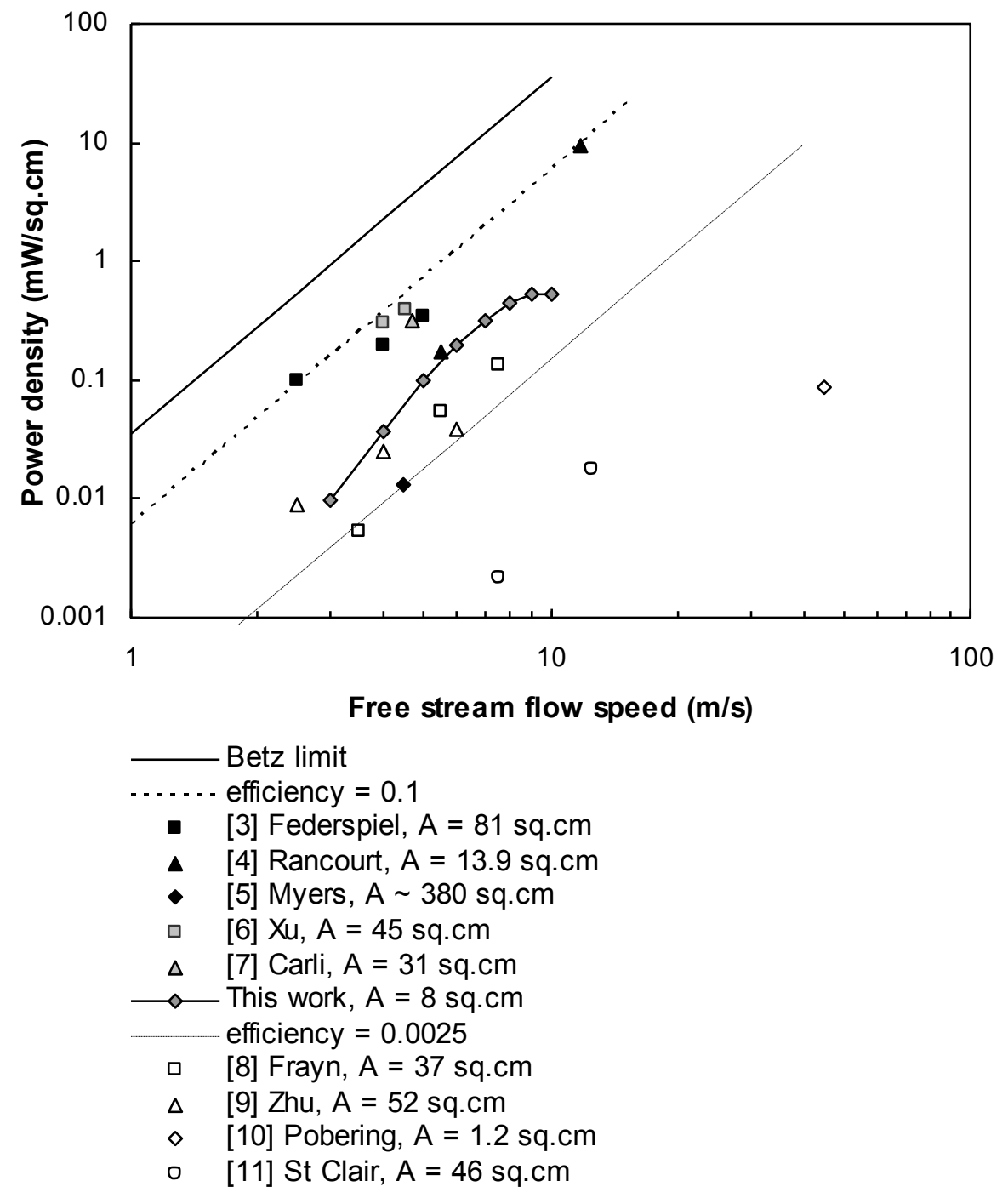

Figure 14: Performance comparison for air flow harvesters reported in the literature, plotted as electrical output power per unit cross-sectional area as a function of free stream flow speed. Both turbine-based (solid symbols) and non-turbine (open symbols) designs are included. In all cases the area used is the entire crosssectional area presented to the flow. 